\title{
Efficient generation of P53 biallelic knockout Diannan miniature pigs via TALENs and somatic cell nuclear transfer
}

Youfeng Shen ${ }^{1,2+}$, Kaixiang Xu' ${ }^{1+}$, Zaimei Yuan 1,2, Jianxiong Guo ${ }^{1}$, Heng Zhao ${ }^{1,2}$, Xuezeng Zhang ${ }^{1,3}$, Lu Zhao ${ }^{1,3}$, Yubo Qing ${ }^{1,2}$, Honghui Li ${ }^{1,2}$, Weirong Pan ${ }^{2}$, Baoyu Jia ${ }^{1,2}$, Hong-Ye Zhao ${ }^{1 *}$ and Hong-Jiang Wei ${ }^{1,2,3^{*}}$

\begin{abstract}
Background: Pigs have many features that make them attractive as biomedical models for various diseases, including cancer. P53 is an important tumor suppressor gene that exerts a central role in protecting cells from oncogenic transformation and is mutated in a large number of human cancers. P53 mutations occur in almost every type of tumor and in over $50 \%$ of all tumors. In a recent publication, pigs with a mutated P53 gene were generated that resulted in lymphoma and renal and osteogenic tumors. However, approximately $80 \%$ of human tumors have dysfunctional P53. A P53-deficient pig model is still required to elucidate.
\end{abstract}

Methods: Transcription activator-like effector nucleases (TALENs) were designed to target porcine P53 exon 4. The targeting activity was evaluated using a luciferase SSA recombination assay. P53 biallelic knockout (KO) cell lines were established from single-cell colonies of fetal fibroblasts derived from Diannan miniature pigs followed by electroporation with TALENs plasmids. One cell line was selected as the donor cell line for somatic cell nuclear transfer (SCNT) for the generation of P53 $\mathrm{KO}$ pigs. P53 KO stillborn fetuses and living piglets were obtained. Gene typing of the collected cloned individuals was performed by T7El assay and sequencing. Fibroblast cells from Diannan miniature piglets with a P53 biallelic knockout or wild type were analyzed for the P53 response to doxorubicin treatment by confocal microscopy and western blotting.

Results: The luciferase SSA recombination assay revealed that the targeting activities of the designed TALENs were 55.35-fold higher than those of the control. Eight cell lines (8/19) were mutated for P53, and five of them were biallelic knockouts. One of the biallelic knockout cell lines was selected as nuclear donor cells for SCNT. The cloned embryos were transferred into five recipient gilts, three of them becoming pregnant. Five live fetuses were obtained from one surrogate by caesarean section after 38 days of gestation for genotyping. Finally, six live piglets and one stillborn piglet were collected from two recipients by caesarean section. Sequencing analyses of the target site confirmed the P53 biallelic knockout in all fetuses and piglets, consistent with the genotype of the donor cells. The GPCR analysis showed that the expression of the P53 mRNA had significant reduction in various tissues of the knockout piglets. Furthermore, confocal microscopy and western blotting analyses demonstrated that the fibroblast cells of Diannan miniature piglets with a P53 biallelic knockout were defective in mediating DNA damage when incubated with doxorubicin.

Conclusion: TALENs combined with SCNT was successfully used to generate P53 KO Diannan miniature pigs. Although these genetically engineered Diannan miniature pigs had no tumorigenic signs, the P53 gene was dysfunctional. We believe that these pigs will provide powerful new resources for preclinical oncology and basic cancer research.

Keywords: P53, TALENs, SCNT, Diannan miniature pig

\footnotetext{
*Correspondence: hyzhao2000@126.com; hongjiangwei@126.com

${ }^{\dagger}$ Youfeng Shen and Kaixiang Xu equally contributed to this work

1 State Key Laboratory for Conservation and Utilization of Bio-Resources

in Yunnan, Yunnan Agricultural University, Kunming 650201, China

Full list of author information is available at the end of the article
} 


\section{Background}

The key tumor suppressor gene P53 plays an important role in a wide range of cellular processes, including apoptosis, cell cycle arrest, senescence, energy metabolism, and anti-oxidant defense [1]. These stress signals stimulate the activation of P53 protein, which is mediated largely through the activity of P53 in transcriptional regulation of its target genes [2-4]. Transactivation-independent activities of P53 have also been described, ranging from transcriptional repression to cytoplasmic and mitochondrial functions [5, 6]. P53 is the most commonly inactivated gene in sporadic human cancers [7]. It was estimated that approximately $80 \%$ of human tumors have dysfunctional P53. P53 mutations occur in almost every type of tumor and in over $50 \%$ of all tumors [8]. Germline P53 mutations in humans cause Li-Fraumeni syndrome, a familial condition characterized by early onset of different tumors $[9,10]$. Moreover, the P53 gene is somatically mutated or deleted in a large number of human cancers, indicating that this tumor suppressor exerts a protective role against oncogenic transformation in multiple tissues [11].

Many P53 modifications have been generated in mice, including knockout and inducible oncogenic activation mutations [12]. Although genetically engineered mouse models have significantly contributed to cancer biology [13], they still have significant limitations in their usefulness for modeling human cancer due to the differences in human and mouse biology $[14,15]$. Since the physiology, anatomy, pathology, genome organization, body weight, and life spans of pigs and miniature pigs are more similar to those of humans, the pig represents an excellent biomedical model compared to rodents for specific human diseases, including cancer $[16,17]$. Recently, the porcine P53 gene was mutated by the introduction of missense mutations via rAAV, and pigs with lymphoma and renal and osteogenic tumors were generated $[18,19]$. However, a porcine P53 deficiency pigs model is still required to elucidate.

The gene targeting efficiency of traditional DNA homologous recombination (HR) technology is extremely low [20]. In many cases, additional cloning or breeding steps are required to produce biallelic mutant animals due to Cre or virus-related vectors commonly inducing DNA single-strand mutations [19, 21]. The transcription activator-like effector nucleases (TALENs) provide a highly efficient and precise means for gene targeting by introducing double-strand breaks (DSB) at preselected sites [22-24]. TALENs has great promise for creating genetically engineered pigs $[22,25,26]$. Recently, we generated GGTA1 knockout Diannan miniature pigs and the MSTN knockout small tail Han sheep by combining TALENs with SCNT $[27,28]$.
In this study, we generated genetically modified Diannan miniature pigs via gene editing in the somatic cells of Diannan miniature pigs using TALEN technology followed by SCNT to produce P53 KO Diannan miniature pigs. Phenotypic characterization of the mutated pigs was also performed. These genetically engineered Diannan miniature pigs will provide a powerful new resource for preclinical oncology and basic cancer research.

\section{Methods \\ Chemicals}

Unless otherwise stated, all chemicals were purchased from Sigma Chemical Co. (St. Louis, MO, USA).

\section{TALEN design and generation}

TALENs targeting exon 4 of the porcine P53 gene (ensemble ID: ENSSSCG00000017950) were designed and assembled by ViewSolid Biotech Company (Beijing, China). The P53 TALENs recognition sequences were as follows: left TALEN $5^{\prime}$-TCTGGAACAGCCAAGT-3 ${ }^{\prime}$ and right TALEN 5'-CCCTCAAGGCCACTGAC-3'. The coding region of TALENs with ForkI was cloned into pCAG vectors. The targeting efficiency of TALEN vectors in vitro was evaluated by a luciferase single strand annealing (SSA) recombination assay as described previously [28].

\section{Cell culture, transfection and selection}

Pig fetal fibroblasts (PFFs) were prepared as previously described [29]. Prior to transfection, the PFFs were thawed and cultured in medium (10\% FBS and 1\% PS) until sub-confluence was reached. Approximately $7 \times 10^{5}$ PFFs in $700 \mu \mathrm{L}$ PBS mixed with $10.5 \mu \mathrm{g}$ of the TALEN plasmid pairs were transfected by electroporation at $250 \mathrm{~V}$ for a single 20-ms pulse (Gene Pulser Xcell Microbial System, Bio-Rad, USA) in a 4-mm gap cuvette. Then, the cells were seeded in $5 \mathrm{~mL}$ of fresh DMEM containing $10 \%$ FBS in a T25 culture flask following a 48-h incubation at $37{ }^{\circ} \mathrm{C}$. The cells were then trypsinsed, and the extremely dilute culture method was used to cultivate the cells and obtain single cell colonies. After 12-14 days, the colonies were assessed via polymerase chain reaction (PCR) (upstream primer, 5'-ACTGCTCTCTGCCCTTG TCTT-3'; downstream primer, 5'-AGAGTGTGATGGG AAGGATGAG-3'), and the amplified fragments were used for genotyping, including restriction endonuclease analysis and sequencing. Finally, we selected positive fibroblasts cell lines with a biallelic $\mathrm{KO}$ as nuclear donors for SCNT.

\section{In vitro maturation of oocytes}

Oocyte collection and culture were performed as previously described [29]. 


\section{SCNT and generation of P53 KO fetuses and piglets}

Somatic cell nuclear transfer (SCNT) was performed as previously described [29]. P53 biallelic knockout fibroblasts (donor cells) were cultured to sub-confluence before nuclear transfer and then injected into the perivitelline space of an enucleated oocyte. The donor cell membrane should be in contact with the oocyte cytoplasmic membrane. Oocyte cytoplasm-cell complexes were then fused and activated by electric pulses. The normal cleavage and blastocyst stages of the oocytes were recorded at 2 and 7 days of culture, respectively. The blastocyst cell number was counted under an ultraviolet light microscope after fixing and Hoechst 33342 staining. Reconstructed embryos cultured for 14 or $16 \mathrm{~h}$ were surgically transferred into five crossbred (large white/landrace duroc) recipient gilts the day after observed estrus. One pregnancy was delivered by cesarean section on day 38 of gestation to establish fetal fibroblast cell lines and genotyping. Pregnancy was confirmed at approximately 23 days after surgical transfer using an ultrasound scanner (HS-101V, Honda Electronics Co., Ltd., Yamazuka, Japan). Fetuses and piglets were recovered with cesarean surgery at different developmental stages. The deliveries were performed by cesarean section on day 111 or 112 of gestation. Diannan miniature pigs of the same age produced by normal sexual reproduction were used as controls.

\section{Detection of gene mutations}

The genomic DNA of each cell colony, fetus and ear tissues from each newborn cloned piglet was extracted with the TIANamp genomic DNA kit (Tiangen, Beijing, China). Mutations in P53 were assessed using PCR followed by T7 endonuclease I (T7EI) digestion. The genotyping primers for P53 were as follows: upstream primer, 5'-ACTGCTCTCTGCCCTTGTCTT-3' and downstream primer, $5^{\prime}$-AGAGTGTGATGGGAAGGATGAG-3'. Briefly, to identify the sequence knockout by TALENs, the PCR products of 19 cell colonies were digested by T7EI. The positive sequence that had not been digested was purified using a gel extraction kit to prepare for cloning using a recombined plasmid with the PMD18-T plasmid vector (Takara) that was sequenced to determine the exact mutant sequences (Sangon Biotech Co., Ltd., Shanghai, China). DNA mutations were identified by sequence alignment between the sequenced allele and the wild-type (WT) allele. Mutation frequencies were calculated as previously described [23]. Cell colonies harboring mutations were cryopreserved for SCNT.

\section{RNA isolation and qPCR}

Various tissues, including heart, liver, spleen, lung, kidney, muscle and brain were obtained from P53 KO and
WT piglets, frozen immediately in liquid nitrogen and stored at $-80{ }^{\circ} \mathrm{C}$ until use. The total RNA of the tissues and cultured cell treatment with and without $100 \mu \mathrm{M}$ of DOX for $24 \mathrm{~h}$ was isolated using TRIzol (Invitrogen, USA) according to the manufacturer's instructions. cDNA was synthesized from total RNA using a Super RT Kit (TakaRa, Dalian, China). The obtained cDNA was used as a template in SYRB green-based q-PCR (CFX-96, Bio-Rad, USA). The primer sequences can be found in Additional file 1: Table S1. The mRNA expression levels of the P53 were assessed by quantitative-polymerase chain reaction (q-PCR). GAPDH was used for normalization.

\section{Protein extraction and immunoblotting}

FFCs were cultured at a density of $1 \times 10^{6} /$ well in a $10-\mathrm{cm}$ plate and treated with or without DOX $(100 \mu \mathrm{mol} / \mathrm{L})$ for $24 \mathrm{~h}$. The cells were harvested and lysed in RIPA lysis buffer (Beyotime, China) with protease inhibitors at $4{ }^{\circ} \mathrm{C}$. After lysis, supernatants were obtained by centrifugation at $14,000 \times g$ for $15 \mathrm{~min}$ at $4{ }^{\circ} \mathrm{C}$. The proteins $(50 \mu \mathrm{g})$ were separated using SDS-PAGE. After electrophoresis, the proteins were transferred to polyvinylidene difluoride (PVDF) membranes and reacted with primary antibodies against P53 (Imaxgen), P21 (Eptomics) and GAPDH (Sigma). After incubation, membranes were washed and incubated with anti-rabbit secondary antibodies (R\&D, USA). The membranes were developed using the ECL detection system (Easysee Western Blot Kit, China) and visualized with an imagining system (Bio-Rad, Universal Hood II, USA).

\section{Confocal fluorescence microscopy}

Fibroblasts cells of P53 $\mathrm{KO}$ and WT piglets $\left(7.5 \times 10^{4}\right)$ cultured in the medium with or without $100 \mu \mathrm{M}$ DOX for $24 \mathrm{~h}$ were fixed in $4 \%(\mathrm{w} / \mathrm{v})$ paraformaldehyde overnight at $4{ }^{\circ} \mathrm{C}$ and permeabilized with $0.05 \%$ Triton X-100 for $30 \mathrm{~min}$. Then, the cells were incubated with an antibody against P53 at $4{ }^{\circ} \mathrm{C}$ overnight. After washing with PBS three times, the cells were incubated with 400 -fold diluted Alexa Fluor 488-labeled anti-mouse IgG (Thermo Fisher). The nuclei of the incubated cells were stained with $5 \mu \mathrm{g} / \mathrm{mL}$ Hoechst 33342, and the cells were observed using confocal fluorescence microscopy (FV1000, Olympus Corporation).

\section{Statistical analysis}

All values were expressed as the mean $\pm \mathrm{SD}$, and they were statistically analyzed by Student's $\mathrm{t}$ test using GraphPad Prism 5 software (La Jolla, CA). ${ }^{*} p<0.05$ and $* * p<0.01$ versus the control were considered as statistically significant. 


\section{Results}

\section{Construction of TALENs targeting P53 gene and validation of activity}

TALEN pairs targeting exon 4 of porcine P53 were commercially synthesized; the constructs were shown in Fig. 1a, b. The activity was validated using the luciferase SSA recombination assay. The luciferase activity of the TALEN pairs targeted-P53 gene was increased 55.35-fold compared to the activity of control (Fig. 1c), indicating that the TALEN pairs were capable of recognizing their target DNA sequences. Thus, the pair of TALEN plasmids that recognized exon 4 of P53 was used to generate genetargeted Diannan miniature pig fetal fibroblast cells.

\section{Generation of P53 mutant Diannan miniature pig fetal fibroblast cells}

The TALEN plasmids were transfected into Diannan miniature pig fetal fibroblast cells via electroporation. After 2 weeks of culture, eight positive colonies were obtained from a total of 19 cell colonies by T7EI assay (Fig. 2a). Then, the positive colonies were genotyped by sequencing, which showed that three were monoallelic $\mathrm{KO}$ and five were biallelic $\mathrm{KO}$ (Fig. 2b). The results showed that the TALEN-mediated targeting efficiency was up to $42 \%$, and five mutant colonies were biallelic KO.

\section{Generation of P53 knockout fetuses and piglets}

One homozygous mutant cell colony (C12\#) was used as donor cells for SCNT. We produced 2068 reconstructed embryos by SCNT. The cleavage and blastocyst formation rates of the embryos were $76.3 \%$ and $26.7 \%$, respectively (Table 1). A total of 1705 cloned embryos were transferred into five surrogates (Table 2), and three of them became pregnant. Five morphologically normal fetuses (Fig. 3a and Table 2) were obtained from one recipient after 38 days, and their primary fibroblasts were isolated and cultured. Sequencing analysis confirmed five fetuses as P53 knockout fetuses in accordance with the C12\# colony (Fig. 3b). Six live piglets and one dead piglet (Fig. 4a and Table 2) were obtained from two recipients after 111 or 112 days. The DNA sequencing showed that all six live piglets carried biallelic mutations in the P53 and the genotype was consistent with the donor cells derived from C12\# colony (Fig. 4b). Four piglets died immediately after birth and the remaining two died at approximately 2 and 5 months (Table 3 ). The mRNA expression level in the various tissues of the P53 biallelic knockout and WT piglets was detected, and the results showed that P53 mRNA expression was significantly reduced compared to the WT, which confirmed the disruption of P53 expression (Fig. 4c).

\section{Functional inactivation of the porcine P53 protein knockout}

It was anticipated that no P53 protein would be produced in P53 knockout pigs. Thus, we tested whether the porcine P53 knockout behaves like its human and mouse orthologs by analyzing its expression and activity in primary pig fetal fibroblasts in the absence or presence of DOX (doxorubicin)-induced DNA damage. As shown in Fig. 5a, comparable levels of P53 protein were induced by doxorubicin in WT fibroblasts, but not in P53 KO fibroblasts. Consistently, western blotting analysis indicated that DNA damage caused by doxorubicin treatment induced the robust protein expression of P53 and P21 in WT fibroblasts, but not in P53 KO fibroblasts (Fig. 5b). Together, these findings confirmed that the porcine P53 protein was functionally defective in P53 KO Diannan miniature pigs, similar to its human and mouse counterparts.

\section{Discussion}

Mice or pigs with P53 mutations are usually generated by the Cre/loxP system and recombinant adeno-associated virus $[18,19,30]$. However, these methods have an extremely low efficiency because of their dependence on homologous recombination [20,31]. Recently, it has been reported that the TALEN system exhibits high targeting efficiency and specificity [32-34]. To date, TALENs have been successfully applied for efficiently targeting genes as well as generating several animal models [35-38]. Furthermore, our previous study showed the TALEN plasmid DNA editing in sheep did not observe detectable off-target effects using whole-genome sequencing [28]. This result suggests that TALEN plasmid DNA editing in Diannan miniature pigs will also have no off-target effects. Therefore, in this study, we used TALEN technology to target genes in porcine somatic cells followed by SCNT to produce P53 KO pigs. As expected, the TALEN targeting efficiency in PFFs was up to $42 \%$. Five were biallelic knockouts, which indicated that TALENs was a more efficient method for disrupting the P53 allele in porcine fibroblast cells. We performed a total of five embryo transfers, resulting in seven $\mathrm{P} 53$ biallelic $\mathrm{KO}$ piglets from two full-term pregnancies (Table 2). In addition, we collected five P53 biallelic KO fetuses from one pregnant sow to establish primary cell lines for future use. The pregnancy rate was $60 \%$, similar with the results of Sieren et al. [19]. Furthermore, the porcine fibroblasts of the P53 biallelic knockout did not respond to Dox, which demonstrated that the P53 gene was dysfunctional in these pigs. Recently, an improved CRISPR/Cas9 system enabled more efficient and more precise gene editing, including a point mutation [39-42], which is promising 


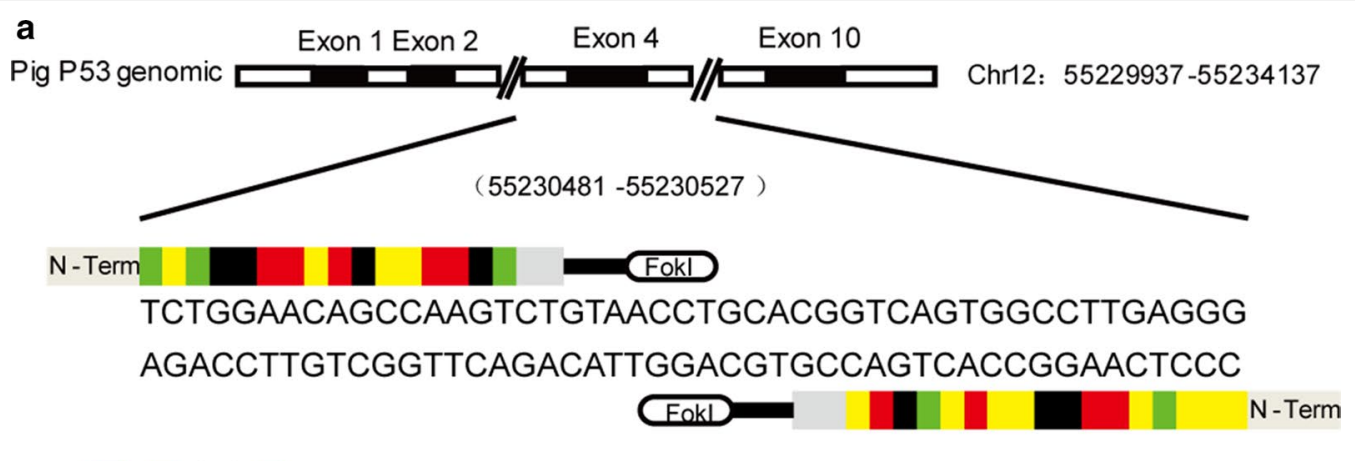

NI HD NN NG

A C G T

b
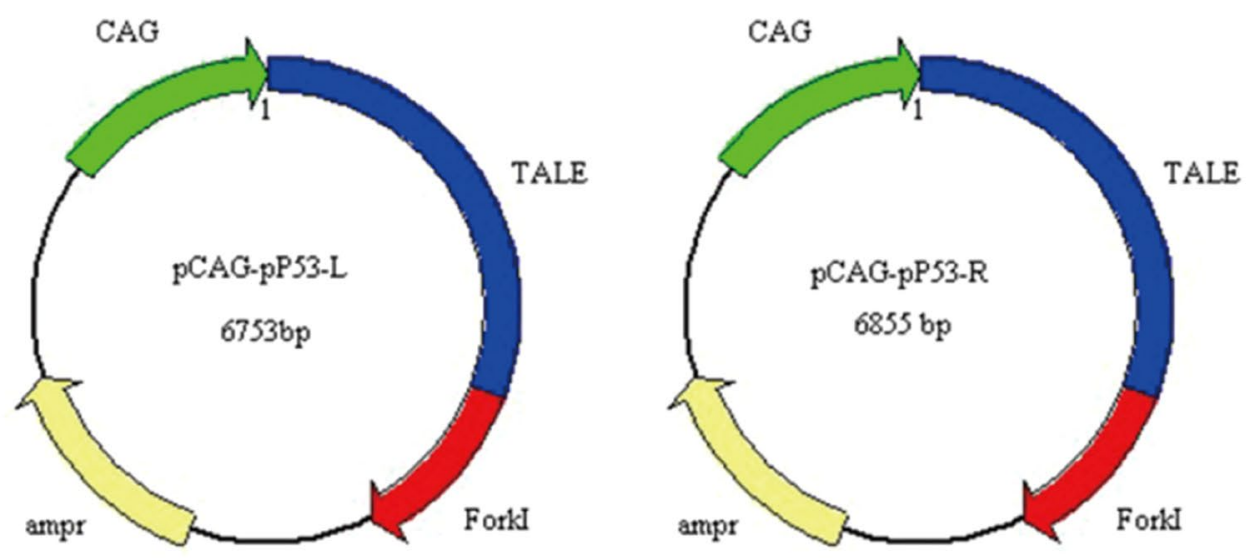

C

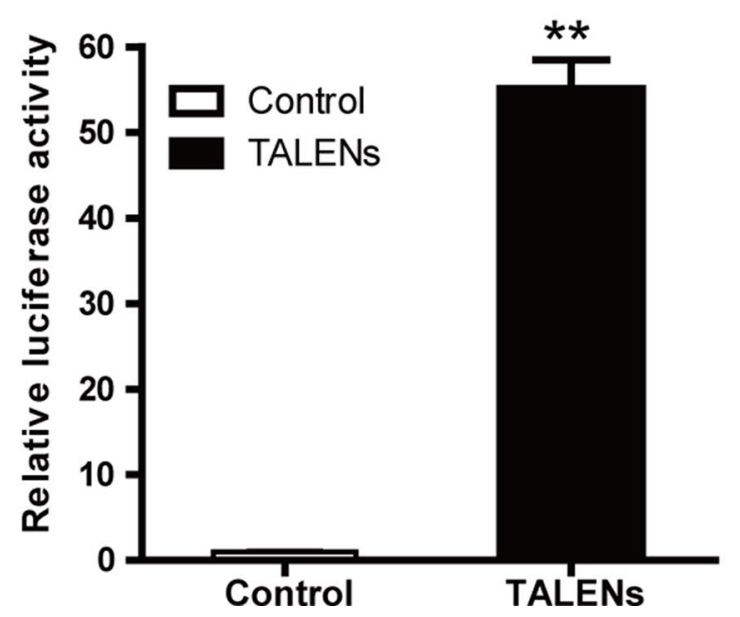

Fig. 1 TALEN design and activity. a A schematic diagram of TALEN targeting exon 4 of the porcine P53 gene. b A schematic diagram of TALEN plasmids specific for P53 gene. $\mathbf{c}$ The detection of TALEN activity using a luciferase SSA recombination assay. Luciferase activity was increased by 55.35-fold compared to the control activity 


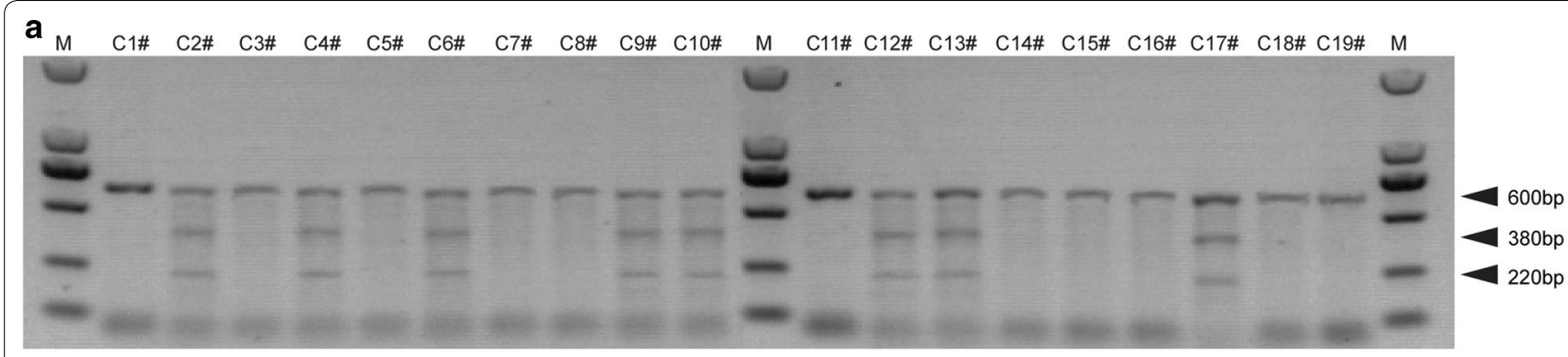

b

WT CTG CAT TCT GGA ACA GCC AAG TCT GTA ACC TGC ACG GTC AGT GGC CTT GAG GGA CTG

C2\# CTG CAT TCT GGA ACA GCC AAG TCT Gg---- TGC ACG GTC AGT GGC CTT GAG GGA CTG CTG CAT TCT GGA ACA GCC AAG TCT GTA AC- TGC ACG GTC AGT GGC CTT GAG GGA CTG $\Delta 1$ CTG CAT TCT GGA ACA GCC AAG TCT GTA AC- TGC ACG GTC AGT GGC CTT GAG GGA CTG $\Delta 1$ CTG CAT TCT GGA ACA GCC AAG TCT GTA --- --C ACG GTC AGT GGC CTT GAG GGA CTG $\triangle 5$ CTG CAT TCT GGA ACA GCC AAG TCT GTA --- --C ACG GTC AGT GGC CTT GAG GGA CTG $\triangle 5$ CTG CAT TCT GGA ACA GCC AAG TC- ------ --- -- G GTC AGT GGC CTT GAG GGA CTG $\quad \Delta 12$ CTG CAT TCT GGA ACA GCC AAG TC---- --- --- --- --- AGT GGC CTT GAG GGA CTG $\Delta 16$ CTG CAT TCT GGA ACA GCC AA---- --- -CC TGC ACG GTC AGT GGC CTT GAG GGA CTG $\Delta 8$ CTG CAT TCT GGA ACA GCC AAG TC---- --- --- --- --- AGT GGC CTT GAG GGA CTG CTG CAT TCT GGA ACA GCC A----- --- ACC TGC ACG GTC AGT GGC CTT GAG GGA CTG $\Delta 8$

CTG CAT TCT GGA ACA GCC AAG TCT GTA ACC TGC ACG GTC AGT GGC CTT GAG GGA CTG WT CTG CAT TCT GGA ACA GCC AAG TCT GTA --C TGC ACG GTC AGT GGC CTT GAG GGA CTG $\Delta 2$ CTG CAT TCT GGA ACA GCC AAG TCT GTA ACC TGC ACG GTC AGT GGC CTT GAG GGA CTG WT CTG CAT TCT GGA ACA GCC AAG TCT GTA -CC TGC ACG GTC AGT GGC CTT GAG GGA CTG $\quad \Delta 1$ CTG CAT TCT GGA ACA GCC AAG TCT GTA ACC TGC ACG GTC AGT GGC CTT GAG GGA CTG WT CTG CAT TCT GGA ACA GCC AAG TCT GTA AC- TGC ACG GTC AGT GGC CTT GAG GGA CTG $\quad \Delta 1$

Fig. 2 TALEN-mediated P53 mutations in PFFs. a Identification of P53-mutant cell lines. Cell lines showing one band indicate the WT allele, while mutated alleles produced three bands in a T7El assay. $\mathbf{b}$ The sequences of P53-mutant cell lines. The WT sequence is shown above. Deletion and point mutations (denoted with " $\triangle$ " and " $p$ " with the number of base pairs) are identified

Table 1 Developmental competence of reconstructed embryos after fusion and electrical activation

\begin{tabular}{lccl}
\hline $\begin{array}{l}\text { No. of embryos } \\
\text { (repeat) }\end{array}$ & Cleavage (\%) & Blastocyst (\%) & $\begin{array}{l}\text { No. of cells } \\
\text { in blastocysts }\end{array}$ \\
\hline $1356(6)$ & $846(76.3 \pm 4.0)$ & $367(26.7 \pm 3.9)$ & $54.6 \pm 13.6$ \\
\hline
\end{tabular}

The percentages are expressed as the Mean \pm SD

for mimicking various human P53 disruptions. Whether it can produce the models simulating various human P53 disruptions with the CRISPR/Cas9 system need to be further investigated.

In previous studies, a mouse model with P53 mutation or deficiency was developed for the study of human tumors [12, 43, 44]. P53-mutant mice are usually used to investigate Li-Fraumeni syndrome, which may cause a variety of tumors, including sarcomas, breast cancers, brain tumors and adrenocortical carcinomas [45]. However, various types of P53 mutation could have different effects on animals, including tumorigenesis and antitumorigenesis [44]. In P53-deficient homozygote mice, the tumors most frequently observed are malignant lymphomas [30, 43, 46, 47]. While mouse tumor models are widely used, their small size and short lifespan preclude some applications in preclinical studies. Pigs are increasingly important in biomedicine and offer valuable complementary resources for cancer research [48-51]. Recently, P53-mutant pigs also have been generated, 
Table 2 Nuclear transfer efficiencies of SCNT

\begin{tabular}{lllllll}
\hline Donor cells & Recipients & Transferred embryos & Days of pregnancy (d) & The pregnancy rate & $\begin{array}{l}\text { Offspring (stillborn/ } \\
\text { aborted) }\end{array}$ & $\begin{array}{l}\text { Mutant piglets or } \\
\text { fetuses }\end{array}$ \\
\hline \multirow{4}{*}{ C12\# } & 1 & 449 & - & $60 \%$ & - & - \\
& 2 & 277 & - & & - & - \\
& 3 & 312 & 38 (cesarean) & & 5 \\
& 4 & 348 & 112 (fetuses) & 2 \\
\\
5
\end{tabular}

a

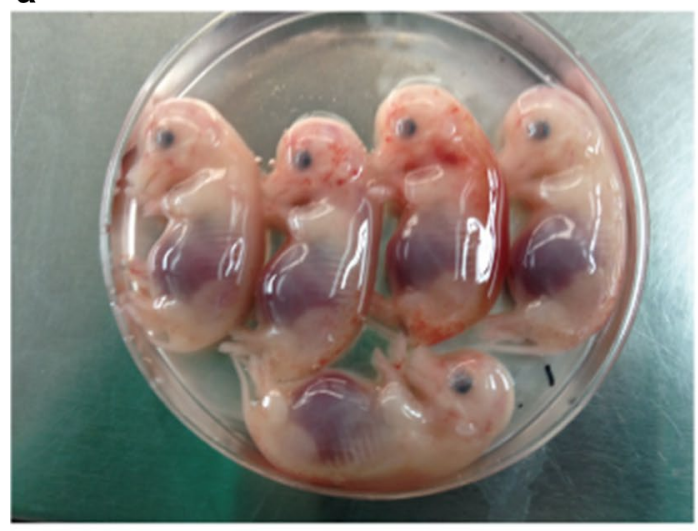

b

WT GTG CAT TCT GGA ACA GCC AAG TCT GTA ACC TGC ACG GTC AGT GGC CTT GAG GGA CTG

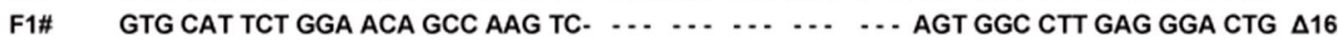

GTG CAT TCT GGA ACA GCC AA - ... ... - .CC TGC ACG GTC AGT GGC CTT GAG GGA CTG $\triangle 8$

F2\# $\quad$ GTG CAT TCT GGA ACA GCC AAG TC $\ldots \ldots \ldots$ GTG CAT TCT GGA ACA GCC AA - . . . . . . - .CC TGC ACG GTC AGT GGC CTT GAG GGA CTG $\Delta 8$

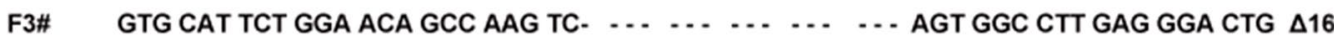
GTG CAT TCT GGA ACA GCC AA - ... ... - -CC TGC ACG GTC AGT GGC CTT GAG GGA CTG $\triangle 8$

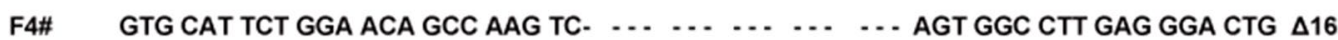
GTG CAT TCT GGA ACA GCC AA - ... . . . - . -CC TGC ACG GTC AGT GGC CTT GAG GGA CTG $\triangle 8$

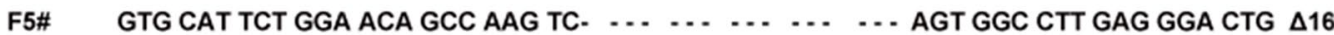
GTG CAT TCT GGA ACA GCC AA - . . . . . . - -CC TGC ACG GTC AGT GGC CTT GAG GGA CTG $\mathbf{\Delta 8}$

Fig. 3 TALEN-mediated P53 mutations in cloned fetuses. a Five P53 KO live fetuses were obtained after 38 days of gestation. $\mathbf{b}$ The sequences of the P53 mutation in the fetuses. The WT sequence is shown above. Deletions (denoted with " $\triangle$ " and the number of base pairs) are identified

which mostly mimic the mutation of the $\mathrm{R} 175 \mathrm{H}$ locus in the human P53 gene, and lymphomas and osteosarcoma have been observed in these pig models $[18,19]$. However, the tumorigenesis types have not been reported in P53-deficient pigs to date.

In this study, of the six live P53 biallelic knockout Diannan miniature pigs, four died immediately after birth, and the remaining two died at approximately 2 and 5 months. These P53 KO pigs were examined by necropsy and hematoxylin-eosin (HE) staining and had no evidence of tumors (data not shown). A recent study reported that although P53 inactivation in pigs was sufficient for spontaneous tumorigenesis, there was also no evidence of tumors or other abnormalities in the animals younger than 16 months [18]. Sieren et al. [19] also reported that necropsy did not reveal any discreet tumors in newborn P53-mutated piglets, although those pigs that reached sexual maturity developed lymphomas and osteogenic and renal tumors. Thus, we infer that our pigs might have not reached the age of tumorigenesis before their 
a

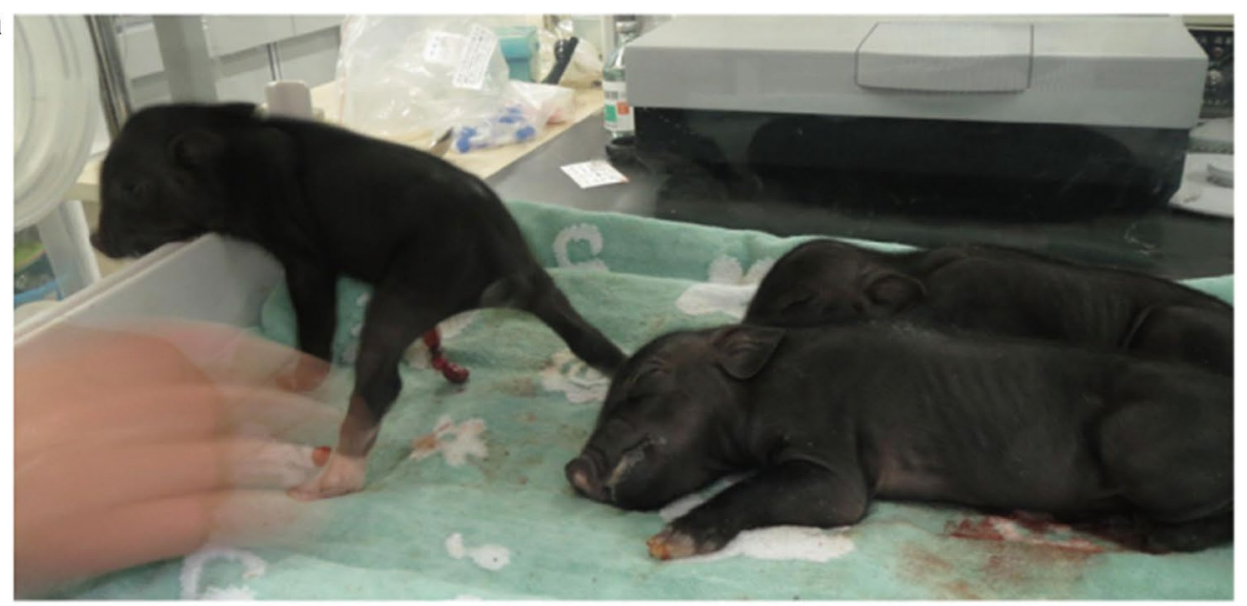

b

WT GTG CAT TCT GGA ACA GCC AAG TCT GTA ACC TGC ACG GTC AGT GGC CTT GAG GGA CTG

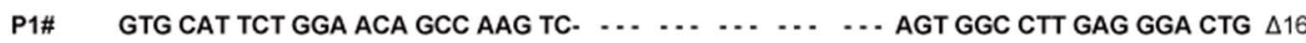
GTG CAT TCT GGA ACA GCC AA - ... . ...

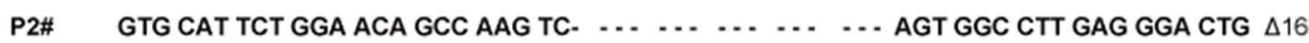
GTG CAT TCT GGA ACA GCC AA . . . . ... .

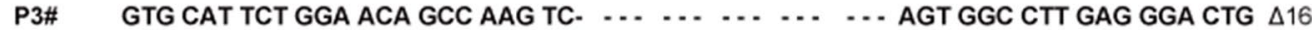
GTG CAT TCT GGA ACA GCC AA $\ldots \ldots \ldots$....

P4\# GTG CAT TCT GGA ACA GCC AAG TC $\ldots \ldots \ldots$ GTG CAT TCT GGA ACA GCC AA $\ldots \ldots \ldots$....

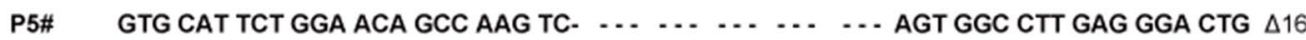
GTG CAT TCT GGA ACA GCC AA . ...........

P6\#

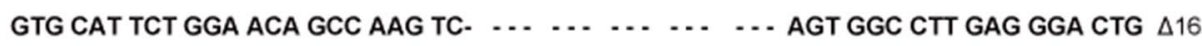
GTG CAT TCT GGA ACA GCC AA . ... .... .

C

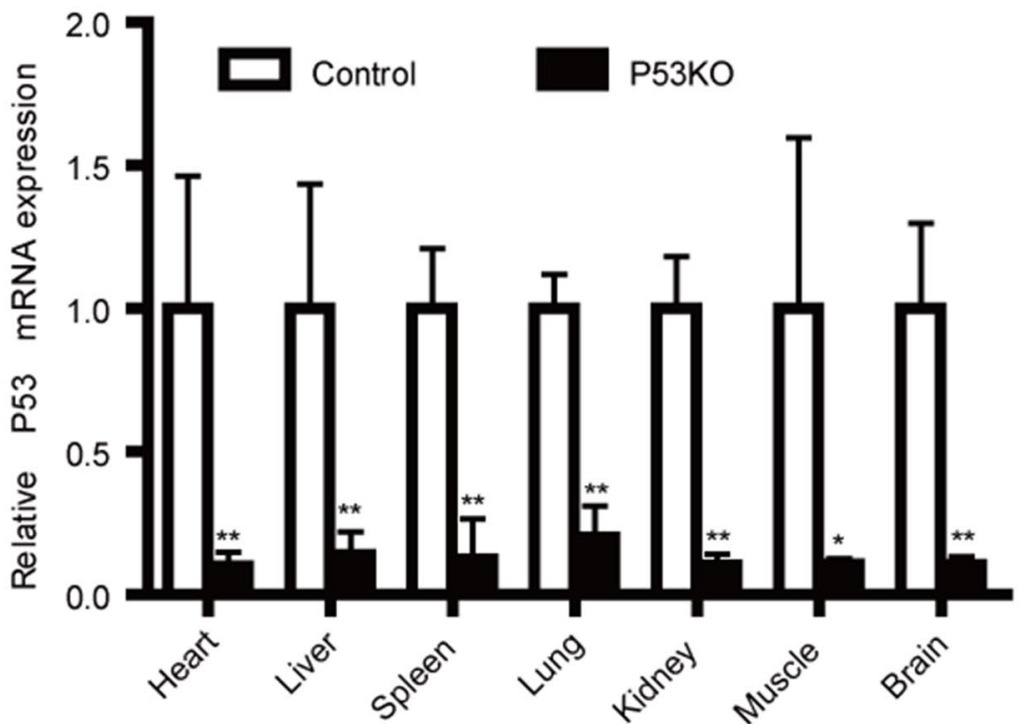

Fig. 4 Identification of transgenic piglets. a Obtained partly P53 KO piglets. b The sequences of the P53 mutation in cloned piglets. The WT sequence is shown above. Deletions (denoted with " $\triangle$ " and the number of base pairs) are identified. $\mathbf{c}$ The relative expression levels of P53 mRNA in the different tissues from P53 KO and WT piglets. The relative expression levels of P53 mRNA in brain, muscle, kidney, heart, liver and kidney tissues of P53 KO and WT piglets were measured using q-PCR. Expression of the GAPDH gene was used to normalize the values of P53. ${ }^{*} p<0.05$ and ${ }^{* *}$ $p<0.01$ denote significant differences in P53 KO piglets compared to WT piglets 
Table 3 The survival time of the P53 KO piglets

\begin{tabular}{ll}
\hline No. of the P53 KO piglets & Survival time of the P53 KO piglets \\
\hline P1\# & 154 days \\
P2\# & 89 min \\
P3\# & 71 days \\
P4\# & 85 min \\
P5\# & 144 min \\
P6\# & $202 \mathrm{~min}$
\end{tabular}

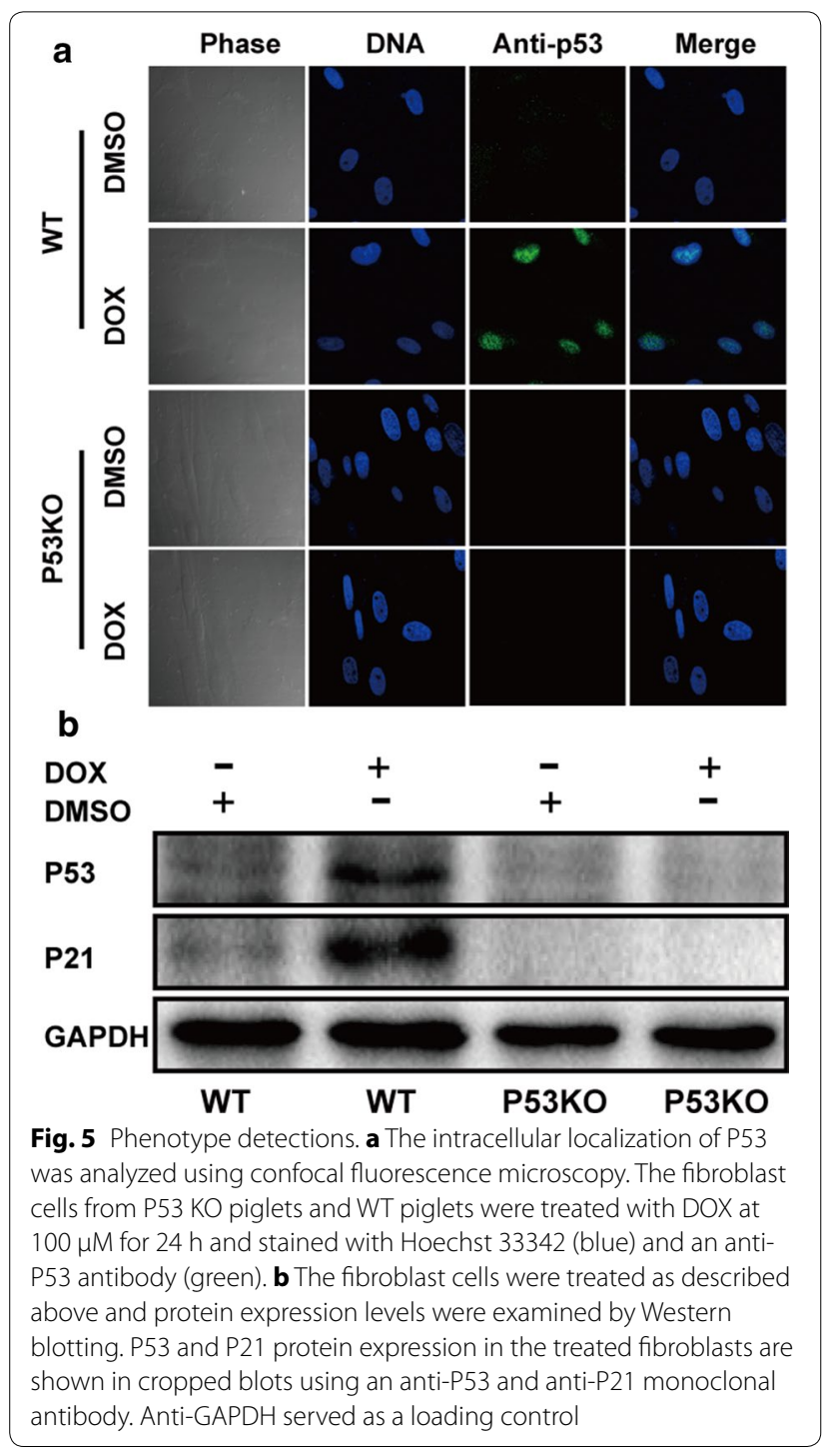

death. A lack of samples also might have led to the failure to find tumors in P53 biallelic KO Diannan miniature pigs. More P53 biallelic KO pigs must be generated, and the tumorigenesis types of P53 KO pigs require further investigation.

\section{Conclusions}

The combination of TALEN gene editing technology and SCNT is effectively used for generating P53 biallelic KO Diannan miniature pigs. Although these genetically engineered Diannan miniature pigs had no tumorigenic signs, the P53 gene was dysfunctional in these pigs. We believe that these pigs will provide powerful new resources for preclinical oncology and basic cancer research.

\section{Additional file}

Additional file 1: Table S1. Primer sequences for the genes.

\begin{abstract}
Abbreviations
rAAV: recombinant adeno-associated virus; TALENs: transcription activator-like effector nucleases; DSB: double-strand break; SCNT: somatic cell nuclear transfer; SSA: single strand annealing; PFFs: pig fetal fibroblasts; T7El: T7 endonuclease I; q-PCR: quantitative-polymerase chain reaction; PVDF: polyvinylidene difluoride; ECL: chemiluminescence; DOX: doxorubicin.
\end{abstract}

\section{Authors' contributions}

HJW and HYZ conceived and designed the experiments. YS, KX, ZY, JG, HZ, $C L, L Z, Y Q, H L, W P, B J$ and HJW performed the experiments. HJW and HYZ analyzed the data. HYZ and KX wrote the paper. All authors reviewed the manuscript. All authors read and approved the final manuscript.

\section{Author details}

${ }^{1}$ State Key Laboratory for Conservation and Utilization of Bio-Resources in Yunnan, Yunnan Agricultural University, Kunming 650201, China. ${ }^{2}$ College of Animal Science and Technology, Yunnan Agricultural University, Kunming, China. ${ }^{3}$ Key Laboratory Animal Nutrition and Feed of Yunnan Province, Yunnan Agricultural University, Kunming 650201, China.

\section{Acknowledgements}

We thank the "National Natural Science Foundation of China" and "Yunnan Provincial Science and Technology Department" for the support provided for this study.

\section{Competing interests}

The authors declare that they have no competing interests.

\section{Availability of data and materials}

All datasets on which the conclusions of the paper rely are available to readers.

\section{Consent for publication}

Not applicable.

\section{Ethics approval}

Animal use and care were in accordance with animal care guidelines that conformed to the Guide for the Care and Use of Laboratory Animals published by the US National Institutes of Health (NIH Publication No. 85-23). The animals used in this study were regularly maintained in the Laboratory Animal Centre of Yunnan Agricultural University. All the animal experiments were performed with the approval of the Animal Care and Use Committee of Yunnan Agricultural University.

\section{Funding}

This work was supported by grants from the National Natural Science Foundation of China (Grant No. 31360549 and 31360549 ), Major Program on Basic Research Projects of Yunnan Province (Grant No. 2014FC006) and the Talent Project of Young and Middle-aged Academic Technology Leadership in Yunnan Province (Grant No. 2013HB073). 


\section{Publisher's Note}

Springer Nature remains neutral with regard to jurisdictional claims in published maps and institutional affiliations.

Received: 28 April 2017 Accepted: 27 October 2017

Published online: 03 November 2017

\section{References}

1. Belyi VA, Ak P, Markert E, Wang H, Hu W, Puzio-Kuter A, Levine AJ. The origins and evolution of the p53 family of genes. Cold Spring Harb Perspect Biol. 2010;2:a001198.

2. Feng Z, Levine AJ. The regulation of energy metabolism and the IGF-1/ mTOR pathways by the p53 protein. Trends Cell Biol. 2010;20:427-34.

3. Sengupta S, Harris CC. p53: traffic cop at the crossroads of DNA repair and recombination. Nat Rev Mol Cell Biol. 2005:6:44-55

4. Vousden $\mathrm{KH}$, Prives $\mathrm{C}$. Blinded by the light: the growing complexity of p53. Cell. 2009:137:413-31.

5. Bohlig L, Rother K. One function-multiple mechanisms: the manifold activities of p53 as a transcriptional repressor. J Biomed Biotechnol. 2011;2011:464916.

6. Brady CA, Attardi LD. p53 at a glance. J Cell Sci. 2010;123:2527-32.

7. Levine AJ, Oren M. The first 30 years of p53: growing ever more complex. Nat Rev Cancer. 2009;9:749-58.

8. Liu J, Zhang C, Feng Z. Tumor suppressor p53 and its gain-of-function mutants in cancer. Acta Biochim Biophys Sin (Shanghai). 2014;46:170-9.

9. Palmero El, Achatz Ml, Ashton-Prolla P, Olivier M, Hainaut P. Tumor protein 53 mutations and inherited cancer: beyond Li-Fraumeni syndrome. Curr Opin Oncol. 2010;22:64-9.

10. Strong LC. General keynote: hereditary cancer: lessons from Li-Fraumeni syndrome. Gynecol Oncol. 2003;88:4-7 (discussion S11-13)

11. Olivier M, Hollstein M, Hainaut P. TP53 mutations in human cancers: origins, consequences, and clinical use. Cold Spring Harb Perspect Biol. 2010;2:a001008

12. Donehower LA, Lozano G. 20 years studying p53 functions in genetically engineered mice. Nat Rev Cancer. 2009;9:831-41.

13. Cheon DJ, Orsulic S. Mouse models of cancer. Annu Rev Pathol. 2011:6:95-119.

14. Flisikowska T, Kind A, Schnieke A. The new pig on the block: modelling cancer in pigs. Transgenic Res. 2013;22:673-80.

15. Gun G, Kues WA. Current progress of genetically engineered pig models for biomedical research. Biores Open Access. 2014:3:255-64.

16. Nowak-Imialek M, Niemann H. Pluripotent cells in farm animals: state of the art and future perspectives. Reprod Fertil Dev. 2012;25:103-28.

17. Whyte JJ, Prather RS. Genetic modifications of pigs for medicine and agriculture. Mol Reprod Dev. 2011;78:879-91.

18. Saalfrank A, Janssen KP, Ravon M, Flisikowski K, Eser S, Steiger K, Flisikowska T, Muller-Fliedner P, Schulze E, Bronner C, et al. A porcine model of osteosarcoma. Oncogenesis. 2016;5:e210.

19. Sieren JC, Meyerholz DK, Wang XJ, Davis BT, Newell JD Jr, Hammond E, Rohret JA, Rohret FA, Struzynski JT, Goeken JA, et al. Development and translational imaging of a TP53 porcine tumorigenesis model. J Clin Invest. 2014;124:4052-66.

20. Horii T, Hatada I. Challenges to increasing targeting efficiency in genome engineering. J Reprod Dev. 2016;62:7-9.

21. Leuchs S, Saalfrank A, Merkl C, Flisikowska T, Edlinger M, Durkovic M Rezaei N, Kurome M, Zakhartchenko V, Kessler B, et al. Inactivation and inducible oncogenic mutation of p53 in gene targeted pigs. PLoS ONE. 2012;7:e43323.

22. Hauschild J, Petersen B, Santiago Y, Queisser AL, Carnwath JW, LucasHahn A, Zhang L, Meng X, Gregory PD, Schwinzer R, et al. Efficient generation of a biallelic knockout in pigs using zinc-finger nucleases. Proc Natl Acad Sci USA. 2011;108:12013-7.

23. Miller JC, Tan S, Qiao G, Barlow KA, Wang J, Xia DF, Meng X, Paschon DE, Leung E, Hinkley SJ, et al. A TALE nuclease architecture for efficient genome editing. Nat Biotechnol. 2011;29:143-8.

24. Urnov FD, Miller JC, Lee YL, Beausejour CM, Rock JM, Augustus S, Jamieson AC, Porteus MH, Gregory PD, Holmes MC. Highly efficient endogenous human gene correction using designed zinc-finger nucleases. Nature. 2005;435:646-51.

25. Carlson DF, Tan W, Lillico SG, Stverakova D, Proudfoot C, Christian M, Voytas DF, Long CR, Whitelaw CB, Fahrenkrug SC. Efficient TALEN-mediated gene knockout in livestock. Proc Natl Acad Sci USA. 2012;109:17382-7.

26. Lee K, Kwon DN, Ezashi T, Choi YJ, Park C, Ericsson AC, Brown AN, Samuel MS, Park KW, Walters EM, et al. Engraftment of human iPS cells and allogeneic porcine cells into pigs with inactivated RAG2 and accompanying severe combined immunodeficiency. Proc Natl Acad Sci USA. 2014;111:7260-5

27. Cheng W, Zhao H, Yu H, Xin J, Wang J, Zeng L, Yuan Z, Oing Y, Li H, Jia B, et al. Efficient generation of GGTA1-null Diannan miniature pigs using TALENs combined with somatic cell nuclear transfer. Reprod Biol Endocrinol. 2016;14(1):77.

28. Li H, Wang G, Hao Z, Zhang G, Qing Y, Liu S, Qing L, Pan W, Chen L, Liu $\mathrm{G}$, et al. Generation of biallelic knock-out sheep via gene-editing and somatic cell nuclear transfer. Sci Rep. 2016;6:33675.

29. Wei H, Qing Y, Pan W, Zhao H, Li H, Cheng W, Zhao L, Xu C, Li H, Li S, et al. Comparison of the efficiency of Banna miniature inbred pig somatic cell nuclear transfer among different donor cells. PLoS ONE. 2013;8:e57728.

30. Chiang YJ, Difilippantonio MJ, Tessarollo L, Morse HC, Hodes RJ. Exon 1 disruption alters tissue-specific expression of mouse p53 and results in selective development of B cell lymphomas. PLoS ONE. 2012;7:e49305.

31. Lewandoski M. Conditional control of gene expression in the mouse. Nat Rev Genet. 2001;2:743-55.

32. Chen $L$, Tang $L$, Xiang $H$, Jin $L$, Li Q, Dong Y, Wang W, Zhang G. Advances in genome editing technology and its promising application in evolutionary and ecological studies. Gigascience. 2014;3:24.

33. Sanjana NE, Cong L, Zhou Y, Cunniff MM, Feng G, Zhang F. A transcription activator-like effector toolbox for genome engineering. Nat Protoc. 2012;7:171-92.

34. Veres A, Gosis BS, Ding Q, Collins R, Ragavendran A, Brand H, Erdin S, Cowan CA, Talkowski ME, Musunuru K. Low incidence of off-target mutations in individual CRISPR-Cas9 and TALEN targeted human stem cell clones detected by whole-genome sequencing. Cell Stem Cell. 2014;15:27-30.

35. Joung JK, Sander JD. TALENs: a widely applicable technology for targeted genome editing. Nat Rev Mol Cell Biol. 2013;14:49-55.

36. Lei $Y$, Guo X, Liu Y, Cao Y, Deng Y, Chen X, Cheng CH, Dawid IB, Chen Y, Zhao H. Efficient targeted gene disruption in Xenopus embryos using engineered transcription activator-like effector nucleases (TALENs). Proc Natl Acad Sci USA. 2012;109:17484-9.

37. Song J, Zhong J, Guo X, Chen Y, Zou Q, Huang J, Li X, Zhang Q, Jiang Z, Tang C, et al. Generation of RAG 1- and 2-deficient rabbits by embryo microinjection of TALENs. Cell Res. 2013;23:1059-62.

38. Tesson L, Usal C, Menoret S, Leung E, Niles BJ, Remy S, Santiago Y, Vincent Al, Meng $X$, Zhang $L$, et al. Knockout rats generated by embryo microinjection of TALENs. Nat Biotechnol. 2011;29:695-6.

39. Maruyama T, Dougan SK, Truttmann MC, Bilate AM, Ingram JR, Ploegh $\mathrm{HL}$. Increasing the efficiency of precise genome editing with CRISPRCas9 by inhibition of nonhomologous end joining. Nat Biotechnol. 2015;33:538-42.

40. Zhao P, Zhang Z, Lv X, Zhao X, Suehiro Y, Jiang Y, Wang X, Mitani S, Gong $H$, Xue D. One-step homozygosity in precise gene editing by an improved CRISPR/Cas9 system. Cell Res. 2016:26:633-6.

41. Mou H, Kennedy Z, Anderson DG, Yin H, Xue W. Precision cancer mouse models through genome editing with CRISPR-Cas9. Genome Med. 2015;7:53.

42. Komor AC, Kim YB, Packer MS, Zuris JA, Liu DR. Programmable editing of a target base in genomic DNA without double-stranded DNA cleavage. Nature. 2016:533:420-4.

43. Donehower LA, Harvey M, Slagle BL, McArthur MJ, Montgomery CA Jr, Butel JS, Bradley A. Mice deficient for p53 are developmentally normal but susceptible to spontaneous tumours. Nature. 1992;356:215-21.

44. Tyner SD, Venkatachalam S, Choi J, Jones S, Ghebranious N, Igelmann H, Lu X, Soron G, Cooper B, Brayton C, et al. p53 mutant mice that display early ageing-associated phenotypes. Nature. 2002;415:45-53.

45. Malkin D, Li FP, Strong LC, Fraumeni JF Jr, Nelson CE, Kim DH, Kassel J, Gryka MA, Bischoff FZ, Tainsky MA, et al. Germ line p53 mutations in a familial syndrome of breast cancer, sarcomas, and other neoplasms. Science. 1990;250:1233-8. 
46. Harvey M, MCArthur MJ, Montgomery CA Jr, Butel JS, Bradley A, Donehower LA. Spontaneous and carcinogen-induced tumorigenesis in p53-deficient mice. Nat Genet. 1993;5:225-9.

47. Jacks T, Remington L, Williams BO, Schmitt EM, Halachmi S, Bronson RT, Weinberg RA. Tumor spectrum analysis in p53-mutant mice. Curr Biol. 1994:4:1-7.

48. Aigner B, Renner S, Kessler B, Klymiuk N, Kurome M, Wunsch A, Wolf E. Transgenic pigs as models for translational biomedical research. J Mol Med (Berl). 2010;88:653-64
49. Flisikowska T, Kind A, Schnieke A. Genetically modified pigs to model human diseases. J Appl Genet. 2014;55:53-64.

50. Luo Y, Lin L, Bolund L, Jensen TG, Sorensen CB. Genetically modified pigs for biomedical research. J Inherit Metab Dis. 2012;35:695-713.

51. Rogers CS. Genetically engineered livestock for biomedical models. Transgenic Res. 2016;25:345-59.

\section{Submit your next manuscript to BioMed Central and we will help you at every step:}

- We accept pre-submission inquiries

- Our selector tool helps you to find the most relevant journal

- We provide round the clock customer support

- Convenient online submission

- Thorough peer review

- Inclusion in PubMed and all major indexing services

- Maximum visibility for your research

Submit your manuscript at www.biomedcentral com/submit 